\title{
Épocas de aplicação de nitrogênio em feijoeiro cultivado após milho solteiro ou consorciado com braquiária
}

\author{
Rogério Peres Soratto(1), Adalton Mazetti Fernandes(1), Cristiane Pilon ${ }^{(2)}$, Carlos Alexandre Costa Crusciol(1) \\ e Emerson Borghi( ${ }^{(3)}$
}

\begin{abstract}
(1)Universidade Estadual Paulista, Faculdade de Ciências Agronômicas, Departamento de Produção e Melhoramento Vegetal, Campus de Botucatu, Caixa Postal 237, CEP 18603-970 Botucatu, SP. E-mail: soratto@fca.unesp.br, adaltonfernandes@hotmail.com, crusciol@fca.unesp.br (2)University of Arkansas, Crop, Soil, and Environmental Sciences Department, 1366 West Altheimer Drive, Fayetteville, AR 72704. E-mail: cristianepilon@yahoo.com.br ${ }^{(3)}$ Embrapa Pesca e Aquicultura, Quadra 104 Sul, Avenida LO I, no 34, Conjunto 04, 1ㅇ e 2o Pavimentos - Plano Diretor Sul, 77015-012 Palmas, TO. E-mail: emerson.borghi@embrapa.br
\end{abstract}

Resumo - O objetivo deste trabalho foi avaliar a resposta do feijoeiro a épocas de aplicação de N, em sistema plantio direto, após cultivo de milho solteiro ou consorciado com braquiária. O delineamento experimental utilizado foi em blocos ao acaso, com arranjo de parcelas subdivididas e quatro repetições. As parcelas consistiram de: cultivo de milho solteiro ou milho consorciado com braquiária, nas duas safras de verão precedentes à semeadura do feijão. As subparcelas consistiram de: três épocas de aplicação de $100 \mathrm{~kg} \mathrm{ha}^{-1}$ de $\mathrm{N}$, antes e na semeadura, e em cobertura; e uma testemunha, sem aplicação de N. A adubação nitrogenada do feijoeiro aumentou o teor de $\mathrm{N}$ na folha, o número de vagens por planta e a produtividade de grãos (33\%, na média das épocas de aplicação), apenas no cultivo em sucessão ao milho solteiro. Por proporcionar maior produção de massa e pela ciclagem de $\mathrm{N}$, o cultivo de braquiária consorciada com milho reduziu a necessidade de aplicação de $\mathrm{N}$ ao feijoeiro em sucessão, em comparação ao cultivo anterior de milho solteiro. A aplicação antecipada do $\mathrm{N}$, antes ou por ocasião da semeadura do feijão, proporciona produtividade de grãos semelhante à observada com a aplicação em cobertura.

Termos para indexação: Brachiaria brizantha, Phaseolus vulgaris, adubação nitrogenada, antecipação, sistema plantio direto.

\section{Timing of nitrogen application on common bean cultivated after single corn or intercropped with palisade grass}

\begin{abstract}
The objective of this work was to evaluate the common bean response to $\mathrm{N}$ application timing, under no-tillage system, after single corn or intercropped with palisade grass. A randomized complete block experimental design was used in a split-plot arrangement, with four replicates. Plots consisted of: single corn crop or corn intercropped with palisade grass, in two summer cropping seasons precedent to common bean sowing. Subplots consisted of: $100 \mathrm{~kg} \mathrm{ha}^{-1} \mathrm{~N}$ application in three times - before sowing, at sowing, and at side-dressing - and a control treatment without $\mathrm{N}$ application. Nitrogen fertilization on common bean increased leaf-N content, the number of pods per plant, and grain yield (33\% in the average application timing), only in the cropping after single corn. By providing large mass production and by $\mathrm{N}$ cycling, the cultivation of palisade grass intercropped with corn reduced $\mathrm{N}$ requirement of common bean in succession, in comparison to previous sole corn cultivation. Early $\mathrm{N}$ application before or during common bean sowing time provides grain yield similar to the observed one in the side-dressing application.
\end{abstract}

Index terms: Brachiaria brizantha, Phaseolus vulgaris, nitrogen fertilization, early application, no-tillage system.

\section{Introdução}

O sistema plantio direto (SPD) tem sido uma das melhores alternativas para a conservação dos recursos naturais, na utilização agrícola dos solos brasileiros. No entanto, um dos principais fatores limitantes do SPD é a dificuldade de manutenção permanente de uma quantidade mínima de palha na superfície do solo, especialmente em regiões com inverno seco, em que a produção de palhada é baixa (Kluthcouski et al., 2000; Crusciol et al., 2009).

Porém, nos últimos anos, o cultivo consorciado de plantas produtoras de grãos com forrageiras tropicais tem aumentado significativamente nessas regiões, 
com produção de forragem no período de menor disponibilidade e palhada para o SPD na safra seguinte (Borghi \& Crusciol, 2007; Borghi et al., 2013; Crusciol et al., 2013). Nesse sistema, o milho consorciado com braquiária, principalmente a espécie Urochloa brizantha (Syn. Brachiaria bryzantha), tem se destacado pela elevada produção de massa e adequada cobertura do solo, sem reduzir a produtividade do milho (Crusciol et al., 2009, 2013; Costa et al., 2012; Borghi et al., 2013), podendo, em alguns casos, até aumentá-la (Borghi \& Crusciol, 2007; Costa et al., 2012).

O feijão (Phaseolus vulgaris L.) é importante na composição de sistemas agrícolas, na região Centro-Sul do Brasil, e é uma das principais culturas anuais cultivadas em SPD. O emprego de técnicas - como a utilização de insumos, manejo adequado da adubação e a inclusão de gramíneas forrageiras - tem permitido a obtenção de produtividade desta cultura bem acima da média nacional (Silveira et al., 2005; Crusciol et al., 2009; Souza \& Soratto, 2012). Contudo, para o feijoeiro expressar todo seu potencial produtivo, é necessário que o fornecimento de $\mathrm{N}$ seja adequado, pois este é o nutriente absorvido em maior quantidade pelo feijoeiro e sua deficiência resulta em menor produtividade de grãos (Oliveira et al., 1996; Soratto et al., 2005; Crusciol et al., 2007).

A recomendação de adubação nitrogenada para o feijoeiro mais rotineiramente preconizada tem sido a aplicação de parte do $\mathrm{N}$ no sulco, junto ao fósforo e ao potássio por ocasião da semeadura, e parte em cobertura (Ambrosano et al., 1997; Barbosa Filho et al., 2005; Vieira, 2006). No entanto, em alguns casos, a utilização de elevadas doses de $\mathrm{N}$ no sulco de semeadura, especialmente associadas à adubação potássica, pode comprometer a população de plantas (Santos \& Fageria, 2007). A aplicação em cobertura onera o custo de produção, pode provocar danos à cultura, em razão do tráfego de maquinário agrícola (Kluthcouski et al., 2006), além de ser menos eficiente do que a aplicação na fase inicial do ciclo da cultura (Soratto et al., 2005; Kluthcouski et al., 2006).

Nascente et al. (2012) verificaram que, para algumas cultivares de feijão, a aplicação de todo o $\mathrm{N}$ incorporado antes da semeadura resultou em produtividade mais elevada. Barbosa Filho et al. (2009) não observaram diferenças na produtividade do feijoeiro cultivado em SPD após o cultivo do milho, quando o $\mathrm{N}$ foi aplicado a lanço, aos 15 dias antes da semeadura ou em cobertura. Binotti (2009) também não constatou diferença na produtividade do feijão em SPD, com a aplicação de $\mathrm{N}$ a lanço sobre a palhada de milho com $U$. brizantha, aos 15 ou 30 dias antes da semeadura, no sulco de semeadura ou em cobertura.

No entanto, ainda são necessárias mais informações com relação à melhor época de aplicação do $\mathrm{N}$, principalmente quando essa cultura é cultivada em sucessão ao milho consorciado com forrageiras perenes, já que a produção de massa vegetal e a quantidade de palhada na superfície do solo são maiores (Crusciol et al., 2009, 2013; Borghi et al., 2013).

O objetivo deste trabalho foi avaliar a resposta do feijoeiro a épocas de aplicação da adubação nitrogenada, quando cultivado na época "das águas", em sistema plantio direto, após o cultivo de milho solteiro ou consorciado com braquiária.

\section{Material e Métodos}

O experimento foi conduzido no ano agrícola 2007/2008, em condições de sequeiro, no Município de Botucatu, SP $\left(22^{\circ} 51^{\prime} \mathrm{S}, 48^{\circ} 26^{\prime} \mathrm{W}\right.$, à altitude de 740 $\mathrm{m})$. Segundo a classificação climática de Köppen, o clima predominante na região é o tropical de altitude, Cwa, caracterizado pelo inverno seco e o verão quente e chuvoso. Os dados meteorológicos foram registrados durante o período de condução do experimento (Tabela 1).

A área utilizada para o experimento foi manejada em SPD, com a sucessão milho/aveia-preta e soja/ aveia-preta, nos anos agrícolas 2001/2002 e 2002/2003, respectivamente. No ano agrícola 2004/2005, as parcelas experimentais foram cultivadas com milho solteiro ou milho consorciado com braquiária ( $U$. brizantha 'Marandu'). Em dezembro de 2005, nas mesmas parcelas experimentais, foram novamente semeados milho solteiro ou milho consorciado com braquiária. Nos dois anos agrícolas, a adubação mineral de semeadura do milho solteiro e do consórcio consistiu da aplicação de $320 \mathrm{~kg} \mathrm{ha}^{-1}$ do fertilizante formulado 08-28-16. À semeadura da forrageira, utilizaram-se $10,0 \mathrm{~kg} \mathrm{ha}^{-1}$ de sementes $(\mathrm{VC}=24 \%$ ), de acordo com recomendações de Kluthcouski et al. (2000). As sementes da forrageira foram misturadas ao adubo e depositadas no compartimento de fertilizante da semeadora, distribuídas à mesma profundidade do adubo e simultaneamente à semeadura da cultura do 
milho. Após a colheita do milho (maio de 2006), a área foi manejada com triturador de palha em meados de maio e agosto de cada ano, até a instalação do experimento a partir de outubro de 2007.

O solo da área experimental é um Latossolo Vermelho distroférrico (Santos et al., 2006). No dia 29/10/2007, antes da aplicação dos tratamentos com $\mathrm{N}$, realizouse a amostragem do solo das parcelas experimentais, para caracterização química e granulométrica da profundidade $0-0,20 \mathrm{~m}$ (Tabela 1 ). O material vegetal coletado das parcelas experimentais, no mesmo dia da amostragem de solo, foi seco em estufa a $65^{\circ} \mathrm{C}$ e, em seguida, realizou-se a pesagem e a transformação dos dados $\left[\mathrm{kg} \mathrm{ha}^{-1}\right.$ de matéria seca (MS)]. O material foi moído para determinação do teor de N (Malavolta et al., 1997) e para o cálculo da quantidade de $\mathrm{N}$ (em kg ha-1) (Tabela 1).

O delineamento experimental de blocos ao acaso foi utilizado em arranjo de parcelas subdivididas, com quatro repetições. As parcelas $(5,4$ x $20 \mathrm{~m})$ foram constituídas por cultivo anterior de milho solteiro ou milho consorciado com braquiária, e as subparcelas $(2,7 \times 10 \mathrm{~m})$ por três épocas de aplicação de $100 \mathrm{~kg} \mathrm{ha}^{-1}$ de $\mathrm{N}$, conforme a seguir: 33 DAS, 33 dias antes da semeadura do feijão (19 dias antes da dessecação das plantas presentes na área); SEM, no mesmo dia da semeadura do feijão; 23 DAE, 23 dias após a emergência (estádio $\mathrm{V}_{4}$ ); e uma testemunha sem aplicação de N. O N foi aplicado a lanço na forma de sulfato de amônio. Cada unidade experimental perfazia uma área total de $27,0 \mathrm{~m}^{2}$, com área útil de $16,2 \mathrm{~m}^{2}$.

No dia 17/10/2007, a área experimental foi submetida à uniformização mecânica, com triturador de palha, à altura de $10 \mathrm{~cm}$. No dia 30/10/2007, realizouse a aplicação de $\mathrm{N}$ de forma antecipada, mediante distribuição a lanço do fertilizante de acordo com os tratamentos. As aplicações de $\mathrm{N}$ foram realizadas em superfície, sem incorporação. Em 18/11/2007, as plantas presentes na área foram dessecadas, mediante aplicação do herbicida glifosato, à dose de $2.160 \mathrm{~g} \mathrm{ha}^{-1}$ i.a. No dia 30/11/2007, aplicou-se à área o herbicida paraquat, à dose de $400 \mathrm{~g} \mathrm{ha}^{-1}$ i.a.

A semeadura do feijão foi realizada mecanicamente, no SPD, em 3/12/2007, durante a época das "águas". A cultivar Pérola foi utilizada, em espaçamento de $0,45 \mathrm{~m}$ entre fileiras e 15 sementes por metro.

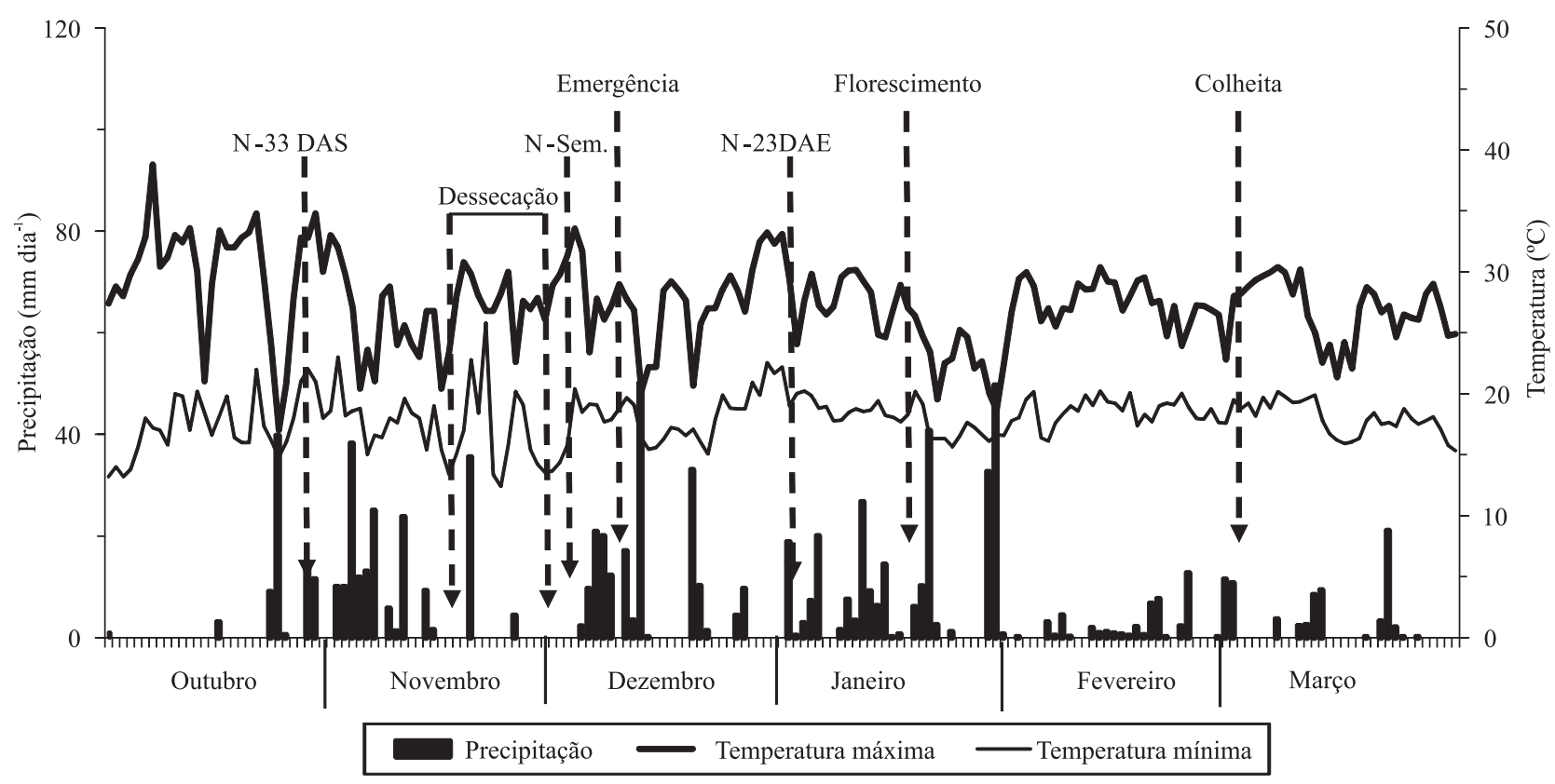

Figura 1. Precipitação pluvial e temperaturas máxima e mínima obtidas na área experimental durante o período de outubro de 2007 a março de 2008, em Botucatu, SP. N-33 DAS, aplicação antecipada de N, 33 dias antes da semeadura do feijão (19 dias antes da dessecação das plantas presentes na área); N-Sem., aplicação de N no mesmo dia da semeadura do feijão; e N-23 DAE, aplicação de N em cobertura, ao feijão, 23 dias após a emergência. Dessecação, manejo químico da área. 
Por ocasião da semeadura, aplicaram-se ao sulco, em todas as parcelas, $45 \mathrm{~kg} \mathrm{ha}^{-1} \mathrm{de}_{2} \mathrm{O}_{5}$ e $48 \mathrm{~kg} \mathrm{ha}^{-1}$ de $\mathrm{K}_{2} \mathrm{O}$, tendo-se utilizado como fontes o superfosfato simples e o cloreto de potássio, respectivamente. Também nessa data, realizou-se a aplicação de $100 \mathrm{~kg} \mathrm{ha}^{-1}$ de N a lanço, de acordo com os tratamentos. A emergência das plantas ocorreu em 11/12/2007.

A aplicação do $\mathrm{N}$ em cobertura foi realizada em $3 / 1 / 2008$, quando as plantas de feijão encontravamse no estádio $\mathrm{V}_{4}$ (terceira folha trifoliada totalmente expandida). A aplicação de $\mathrm{N}$ foi sempre realizada em superfície, sem incorporação. À testemunha também foi aplicado enxofre (S), na forma de gesso agrícola, para o fornecimento da mesma dose de $\mathrm{S}$ para todos os tratamentos. O gesso foi aplicado no mesmo dia da semeadura, a lanço e sem incorporação.

Por ocasião do florescimento pleno (18/1/2008), coletaram-se aleatoriamente 10 plantas por unidade experimental. As plantas foram secas em estufa a $65^{\circ} \mathrm{C}$ e pesadas. As plantas coletadas para determinação da MS, após pesagem, foram moídas e submetidas à análise do teor de $\mathrm{N}$ (Malavolta et al., 1997). Com esses resultados, estimaram-se as quantidades de $\mathrm{N}$ absorvidas por área, mediante a contagem do número

Tabela 1. Características químicas e granulométricas do solo, à profundidade de $0-20 \mathrm{~cm}$, e da cobertura vegetal do solo nas áreas com cultivo anterior de milho solteiro e milho consorciado, antes da aplicação dos tratamentos na área experimental.

\begin{tabular}{|c|c|c|}
\hline \multirow[t]{2}{*}{ Características } & \multicolumn{2}{|c|}{ Cultura antecessora } \\
\hline & Milho solteiro & Milho+braquiária $^{(1)}$ \\
\hline \multicolumn{3}{|l|}{ Solo } \\
\hline $\mathrm{pH}\left(\mathrm{CaCl}_{2}\right)$ & 5,1 & 5,1 \\
\hline $\operatorname{MO}\left(\mathrm{g} \mathrm{dm}^{-3}\right)$ & 31,9 & 30,0 \\
\hline $\mathrm{P}\left(\mathrm{mg} \mathrm{dm}{ }^{-3}\right)$ & 10,3 & 9,7 \\
\hline $\mathrm{H}+\mathrm{Al}\left(\mathrm{mmol}_{\mathrm{c}} \mathrm{dm}^{-3}\right)$ & 41,6 & 43,2 \\
\hline $\mathrm{K}\left(\mathrm{mmol}_{\mathrm{c}} \mathrm{dm}^{-3}\right)$ & 2,3 & 1,4 \\
\hline $\mathrm{Ca}\left(\mathrm{mmol}_{\mathrm{c}} \mathrm{dm}^{-3}\right)$ & 27,9 & 22,0 \\
\hline $\operatorname{Mg}\left(\mathrm{mmol}_{\mathrm{c}} \mathrm{dm}^{-3}\right)$ & 12,1 & 10,4 \\
\hline $\mathrm{CTC}\left(\mathrm{mmol}_{\mathrm{c}} \mathrm{dm}^{-3}\right)$ & 84,0 & 77,0 \\
\hline $\mathrm{V}(\%)$ & 51 & 45 \\
\hline $\mathrm{S}-\mathrm{SO}_{4}{ }^{2-}\left(\mathrm{mg} \mathrm{dm}^{-3}\right)$ & 7,9 & 5,1 \\
\hline Areia $\left(\mathrm{g} \mathrm{kg}^{-1}\right)$ & \multicolumn{2}{|r|}{280} \\
\hline Silte $\left(\mathrm{g} \mathrm{kg}^{-1}\right)$ & \multicolumn{2}{|r|}{90} \\
\hline $\operatorname{Argila}\left(\mathrm{g} \mathrm{kg}^{-1}\right)$ & \multicolumn{2}{|r|}{630} \\
\hline \multicolumn{3}{|l|}{ Cobertura vegetal } \\
\hline Matéria seca $\left(\mathrm{kg} \mathrm{ha}^{-1}\right)$ & 12.311 & 20.415 \\
\hline Teor de $\mathrm{N}\left(\mathrm{g} \mathrm{kg}^{-1}\right)$ & 20,4 & 18,4 \\
\hline Quantidade de $\mathrm{N}$ acumulada $\left(\mathrm{kg} \mathrm{ha}^{-1}\right)$ & 251 & 376 \\
\hline
\end{tabular}

${ }^{(1)} U$. brizantha 'Marandu'; $\mathrm{n}=4$. de plantas em $5 \mathrm{~m}$ de duas linhas da área útil de cada unidade experimental.

Para a determinação de $\mathrm{N}$ na folha, foram amostradas aleatoriamente 10 plantas por unidade experimental (terceiras folhas com pecíolo) (Ambrosano et al., 1997). $\mathrm{O}$ material foi secado em estufa a $65^{\circ} \mathrm{C}$ e, em seguida, as plantas foram moídas para posterior determinação do teor de N (Malavolta et al., 1997).

Por ocasião da colheita do feijão (3/3/2008), determinaram-se os componentes da produção (população final de plantas, número de vagens por planta, número médio de grãos por vagem e massa de 100 grãos) e a produtividade de grãos. Da área útil de cada unidade experimental, foram colhidas manualmente as plantas contidas em duas linhas de $5 \mathrm{~m}$ de comprimento. Após a trilha mecânica e a limpeza, os grãos foram pesados e, posteriormente, foi calculada a produtividade de grãos (em kg ha $\left.{ }^{-1}\right)$, a 13\% de umidade (base úmida).

Os resultados foram submetidos à análise de variância, e as médias foram comparadas pelo teste de Tukey, a 5\% de probabilidade, pelo programa Sisvar.

\section{Resultados e Discussão}

Os fatores estudados não influenciaram a população de plantas ao florescimento nem o teor de $\mathrm{N}$ da parte aérea do feijoeiro, que foram em média de 188.745 plantas ha ${ }^{-1}$ e $30,7 \mathrm{~g} \mathrm{~kg}^{-1}$, respectivamente (Tabela 2). A produção de MS da parte aérea e a quantidade de $\mathrm{N}$ acumulada pelo feijoeiro foram influenciadas apenas pelas épocas de aplicação do $\mathrm{N}$. A adubação nitrogenada aumentou a produção de MS da parte aérea do feijoeiro, resultado que também foi observado por outros autores, em feijoeiro cultivado em SPD (Soratto et al., 2005; Crusciol et al., 2007). $\mathrm{O}$ aumento da MS da parte aérea está relacionado ao maior teor de $\mathrm{N}$ nas folhas proporcionado pela adubação nitrogenada (Tabela 3). Este nutriente aumenta os níveis de fotossíntese líquida, o que resulta em maior acúmulo de MS (Crusciol et al., 2007). Não houve diferenças de produção de MS do feijoeiro entre as épocas de aplicação do $\mathrm{N}$, o que indica que, no SPD, a aplicação de $\mathrm{N}$ a lanço, antes ou no mesmo dia da semeadura, proporciona crescimento das plantas semelhante ao obtido com a aplicação em cobertura.

A quantidade de $\mathrm{N}$ acumulada pelo feijoeiro não diferiu entre as épocas de aplicação, mas a aplicação a lanço, no mesmo dia da semeadura, ou em cobertura 
resultou em maior acúmulo desse nutriente pelo feijoeiro do que no tratamento sem aplicação de $\mathrm{N}$ (Tabela 2). Apesar de a aplicação antecipada de $\mathrm{N}$ ter resultado em acúmulo de $\mathrm{N}$ estatisticamente similar ao da testemunha, houve resposta do feijoeiro à adubação nitrogenada, com aumentos de $35,3 \%$ na produção de MS e de 30,5\% no acúmulo de $\mathrm{N}$ na parte aérea, no tratamento com aplicação do $\mathrm{N}$ aos 33 DAS, em comparação à testemunha. Souza \& Soratto (2012) também observaram aumento da produção de MS e da quantidade de $\mathrm{N}$ acumulada na parte aérea do feijoeiro cultivado em SPD, após o cultivo de milho consorciado com braquiárias ( $U$. brizantha e $U$. ruziziensis), mesmo com teores considerados adequados de $\mathrm{N}$, na folha-diagnose da testemunha.

Os teores de $\mathrm{N}$ na folha não diferiram entre os sistemas de cultivo antecessores, na presença da adubação nitrogenada (Tabela 3). Nos tratamentos sem aplicação de $\mathrm{N}$, os teores foliares de $\mathrm{N}$ foram maiores nas plantas de feijão cultivadas em sucessão ao consórcio. A adubação nitrogenada aumentou os teores foliares de $\mathrm{N}$ do feijoeiro, principalmente no cultivo após milho solteiro, enquanto no cultivo em sucessão ao consórcio, apenas a aplicação de $\mathrm{N}$ em cobertura resultou em teores foliares maiores do que os da testemunha. Somente nos tratamentos que receberam adubação nitrogenada e na testemunha cultivada em sucessão ao consórcio, os teores foliares de $\mathrm{N}$ ficaram dentro da faixa de 30 a $50 \mathrm{~g} \mathrm{~kg}^{-1}$, considerada adequada por Ambrosano et al. (1997).
No tratamento sem adubação nitrogenada, os elevados teores de $\mathrm{N}$ nas folhas do feijoeiro cultivado em sucessão a milho + braquiária indicaram que a inclusão da forrageira disponibilizou maior quantidade de $\mathrm{N}$ para o feijão (Tabela 3 ), em consequência da maior quantidade de MS e $\mathrm{N}$ na cobertura vegetal (Tabela 1). Aidar et al. (2000), apenas três meses após a colheita do milho, observaram acúmulo de $10.490 \mathrm{~kg} \mathrm{ha}^{-1}$ de resíduos em área com cultivo de milho solteiro, na safra verão, e $16.020 \mathrm{~kg} \mathrm{ha}^{-1}$ do cultivo de milho $+U$. brizantha. Destaca-se que, no presente trabalho, o consórcio milho + braquiária foi cultivado na área por dois anos consecutivos (safras verão 2004/2005 e 2005/2006), e a forrageira permaneceu na área por aproximadamente 18 meses, entre a colheita da última safra de milho e a dessecação para a semeadura do feijão, o que proporcionou elevado acúmulo de biomassa (Tabela 1). De acordo com Crusciol et al. (2009), as forrageiras, no sistema consorciado, apresentam elevado potencial de ciclagem de nutrientes. Porém, Souza \& Soratto (2012) verificaram que, mesmo havendo disponibilidade de $\mathrm{N}$, proveniente da mineralização da palhada de milho $+U$. brizantha e milho $+U$. ruziziensis, a aplicação de $\mathrm{N}$ em cobertura aumentou o teor desse nutriente nas folhas do feijão.

A população final de plantas não foi afetada pelos fatores estudados, e o valor médio obtido foi de 160.664 plantas ha ${ }^{-1}$ (Tabela 4). Apesar de a população de plantas ter ficado abaixo da preestabelecida na semeadura

Tabela 2. População de plantas, matéria seca, teor de $\mathrm{N}$ e quantidade de $\mathrm{N}$ acumulada na parte aérea, no estádio de florescimento do feijoeiro cultivado em sistema plantio direto, após milho solteiro ou milho consorciado, em função de épocas de aplicação da adubação nitrogenada. ${ }^{(1)}$

\begin{tabular}{|c|c|c|c|c|}
\hline Tratamento & $\begin{array}{l}\text { População ao } \\
\text { florescimento } \\
(\text { plantas ha-1) }\end{array}$ & $\begin{array}{c}\text { Matéria seca } \\
\text { da parte aérea } \\
\left(\mathrm{kg} \mathrm{ha}^{-1}\right)\end{array}$ & $\begin{array}{c}\text { Teor de } \mathrm{N} \mathrm{da} \\
\text { parte aérea } \\
\left(\mathrm{g} \mathrm{kg}^{-1}\right)\end{array}$ & $\begin{array}{c}\text { Quantidade de } \mathrm{N} \\
\text { acumulada } \\
\left(\mathrm{kg} \mathrm{ha}^{-1}\right)\end{array}$ \\
\hline \multicolumn{5}{|l|}{ Cultura antecessora } \\
\hline Milho solteiro & $190.963 \mathrm{a}$ & $2.585 \mathrm{a}$ & $30,6 \mathrm{a}$ & $79,0 \mathrm{a}$ \\
\hline Milho + braquiária ${ }^{(2)}$ & $186.527 \mathrm{a}$ & $2.465 \mathrm{a}$ & $30,7 \mathrm{a}$ & $75,7 \mathrm{a}$ \\
\hline CV (\%) & 13,6 & 13,6 & 31,1 & 32,1 \\
\hline \multicolumn{5}{|c|}{ Época de aplicação do $\mathrm{N}^{(3)}$} \\
\hline Testemunha & $191.990 \mathrm{a}$ & $1.876 \mathrm{~b}$ & $29,6 \mathrm{a}$ & $55,5 \mathrm{~b}$ \\
\hline 33 DAS & $179.907 \mathrm{a}$ & $2.539 \mathrm{a}$ & $28,5 \mathrm{a}$ & $72,4 \mathrm{ab}$ \\
\hline SEM & $190.231 \mathrm{a}$ & $2.767 \mathrm{a}$ & $29,7 \mathrm{a}$ & $82,1 \mathrm{a}$ \\
\hline $23 \mathrm{DAE}$ & $192.851 \mathrm{a}$ & $2.917 \mathrm{a}$ & $34,8 \mathrm{a}$ & $101,4 \mathrm{a}$ \\
\hline CV (\%) & 10,4 & 16,5 & 23,1 & 29,3 \\
\hline
\end{tabular}

${ }^{(1)}$ Médias seguidas de letras iguais, nas colunas, dentro de cada fator, não diferem entre si, pelo teste de Tukey, a $5 \%$ probabilidade. (2) $U$. brizantha 'Marandu'. ${ }^{(3)}$ Dose de N (100 kg ha-1) aplicada a lanço, nas épocas: 33 DAS, 33 dias antes da semeadura do feijão (19 dias antes da dessecação das plantas presentes na área); SEM, no mesmo dia da semeadura do feijão; e 23 DAE, em cobertura, ao feijoeiro, 23 dias após a emergência. 
(300 mil plantas por hectare), provavelmente em razão de problemas no vigor das sementes, a produtividade de grãos foi elevada, inclusive no tratamento testemunha (acima de $2.500 \mathrm{~kg} \mathrm{ha}^{-1}$ ), o que se deve à elevada capacidade de compensação da cultivar Pérola (Tabela 5). Arf et al. (2011), em estudo com esta cultivar, também obtiveram produtividade elevada de grãos (entre 2.600 a $2.900 \mathrm{~kg} \mathrm{ha}^{-1}$ ), no segundo ano de

Tabela 3. Desdobramento da interação entre cultura antecessora e épocas de aplicação da adubação nitrogenada, quanto ao teor de $\mathrm{N}\left(\mathrm{g} \mathrm{kg}^{-1}\right)$ nas folhas do feijoeiro ${ }^{(1)}$.

\begin{tabular}{lcc}
\hline Época de & \multicolumn{2}{c}{ Cultura antecessora } \\
\cline { 2 - 3 } aplicação $^{(2)}$ & Milho solteiro & \multicolumn{1}{c}{ Milho + braquiária ${ }^{(3)}$} \\
\hline Testemunha & $29,4 \mathrm{bB}$ & $37,9 \mathrm{bA}$ \\
$33 \mathrm{DAS}$ & $41,1 \mathrm{aA}$ & $40,0 \mathrm{abA}$ \\
$\mathrm{SEM}$ & $42,6 \mathrm{aA}$ & $45,6 \mathrm{abA}$ \\
$23 \mathrm{DAE}$ & $42,9 \mathrm{aA}$ & $48,3 \mathrm{aA}$ \\
\hline $\mathrm{CV}_{\text {parcela }}(\%)$ & \multicolumn{3}{|}{6,3} \\
$\mathrm{CV}_{\text {subparcela }}(\%)$ & \multicolumn{3}{c}{11,4} \\
\hline
\end{tabular}

${ }^{(1)}$ Médias seguidas de letras iguais, maiúsculas nas linhas e minúsculas nas colunas, dentro de cada fator, não diferem entre si, pelo teste de Tukey, a $5 \%$ probabilidade. ${ }^{(2)}$ Dose de $\mathrm{N}\left(100 \mathrm{~kg} \mathrm{ha}^{-1}\right)$ aplicada a lanço, nas épocas: 33 DAS, 33 dias antes da semeadura do feijão (19 dias antes da dessecação das plantas presentes na área); SEM, no mesmo dia da semeadura do feijão; e 23 DAE, em cobertura, ao feijoeiro, 23 dias após a emergência. ${ }^{(3)}$ U. brizantha 'Marandu'.

Tabela 4. População final de plantas, número de grãos por vagem e massa de 100 grãos do feijoeiro, cultivado no sistema plantio direto após milho solteiro ou milho consorciado com braquiária, em função de épocas de aplicação da adubação nitrogenada ${ }^{(1)}$.

\begin{tabular}{lccc}
\hline Tratamento & $\begin{array}{c}\text { População final } \\
\left(\text { plantas ha }^{-1}\right)\end{array}$ & $\begin{array}{c}\text { Grãos por } \\
\text { vagem }\end{array}$ & $\begin{array}{c}\text { Massa de } \\
100 \text { grãos }(\mathrm{g})\end{array}$ \\
\hline Cultura antecessora & & & \\
$\quad$ Milho solteiro & $158.826 \mathrm{a}$ & $5,3 \mathrm{a}$ & $26,3 \mathrm{a}$ \\
Milho + braquiária ${ }^{(2)}$ & $162.502 \mathrm{a}$ & $5,3 \mathrm{a}$ & $26,2 \mathrm{a}$ \\
\hline CV(\%) & 15,9 & 2,8 & 2,0 \\
\hline Época de aplicação do $\mathrm{N}^{(3)}$ & & & \\
$\quad$ Testemunha & $162.454 \mathrm{a}$ & $5,4 \mathrm{a}$ & $26,7 \mathrm{a}$ \\
33 DAS & $153.287 \mathrm{a}$ & $5,2 \mathrm{a}$ & $26,7 \mathrm{a}$ \\
SEM & $160.657 \mathrm{a}$ & $5,2 \mathrm{a}$ & $25,2 \mathrm{a}$ \\
23 DAE & $166.259 \mathrm{a}$ & $5,2 \mathrm{a}$ & $26,4 \mathrm{a}$ \\
\hline $\mathrm{CV}(\%)$ & 11,6 & 8,7 & 4,9 \\
\hline
\end{tabular}

${ }^{(1)}$ Médias seguidas de letras iguais, nas colunas, dentro de cada fator, não diferem entre si, pelo teste de Tukey, a $5 \%$ probabilidade. ${ }^{(2)} U$. brizantha 'Marandu'. ${ }^{(3)}$ Dose de N (100 kg ha $\left.{ }^{-1}\right)$ aplicada a lanço, nas épocas: 33 DAS, 33 dias antes da semeadura do feijão (19 dias antes da dessecação das plantas presentes na área); SEM, no mesmo dia da semeadura do feijão; e 23 DAE, em cobertura, ao feijoeiro, 23 dias após a emergência. cultivo de feijão em SPD, após milho consorciado com braquiária, mesmo com população média de plantas de 158 mil plantas por hectare.

O número de grãos por vagem e a massa de 100 grãos não foram afetados pelos fatores estudados (Tabela 4). Apesar de Oliveira et al. (1996) citarem que plantas de feijão deficientes em $\mathrm{N}$ produzem poucas sementes por vagem e sementes pequenas, Soratto et al. (2004) e Crusciol et al. (2007) também não verificaram efeito da aplicação de $\mathrm{N}$ no número de grãos por vagem e atribuíram isso ao fato de se tratar de uma característica de alta herdabilidade genética e pouco influenciada pelo ambiente. Da mesma forma, a massa de grãos é característica que também apresenta pequena variação em razão das alterações no meio de cultivo (Silveira et al., 2005; Soratto et al., 2005; Crusciol et al., 2007).

O número de vagens por planta aumentou com a adubação nitrogenada, apenas quando o feijoeiro foi cultivado em sucessão ao milho solteiro (Tabela 5). $\mathrm{O}$ maior número de vagens obtido em resposta à aplicação de $\mathrm{N}$ está relacionado ao aumento da MS, pois, plantas maiores e com maior quantidade de ramificações produzem maior número de estruturas

Tabela 5. Desdobramento da interação entre cultura antecessora e épocas de aplicação da adubação nitrogenada, quanto ao número de vagens por planta e produtividade de grãos do feijoeiro ${ }^{(1)}$.

\begin{tabular}{|c|c|c|}
\hline \multirow{2}{*}{$\begin{array}{l}\text { Época de } \\
\text { aplicaçãa }^{(2)}\end{array}$} & \multicolumn{2}{|c|}{ Cultura antecessora } \\
\hline & Milho solteiro & Milho + braquiária $^{(3)}$ \\
\hline & \multicolumn{2}{|c|}{ Número de vagens por planta } \\
\hline Testemunha & $8,4 \mathrm{bB}$ & $12,3 \mathrm{aA}$ \\
\hline 33 DAS & $14,0 \mathrm{aA}$ & $14,3 \mathrm{aA}$ \\
\hline SEM & $12,4 \mathrm{abA}$ & $14,4 \mathrm{aA}$ \\
\hline $23 \mathrm{DAE}$ & $15,9 \mathrm{aA}$ & $14,1 \mathrm{aA}$ \\
\hline $\mathrm{CV}_{\text {parcela }}(\%)$ & \multicolumn{2}{|c|}{8,7} \\
\hline $\mathrm{CV}_{\text {subparcela }}(\%)$ & \multicolumn{2}{|c|}{19,0} \\
\hline & \multicolumn{2}{|c|}{ Produtividade de grãos $\left(\mathrm{kg} \mathrm{ha}^{-1}\right)$} \\
\hline Testemunha & $2.549 \mathrm{bA}$ & $2.939 \mathrm{aA}$ \\
\hline 33 DAS & $3.366 \mathrm{aA}$ & $3.072 \mathrm{aA}$ \\
\hline SEM & $3.538 \mathrm{aA}$ & $2.850 \mathrm{aB}$ \\
\hline $23 \mathrm{DAE}$ & $3.258 \mathrm{abA}$ & $3.557 \mathrm{aA}$ \\
\hline $\mathrm{CV}_{\text {parcela }}(\%)$ & \multicolumn{2}{|c|}{10,4} \\
\hline $\mathrm{CV}_{\text {subparcela }}(\%)$ & \multicolumn{2}{|c|}{11,6} \\
\hline
\end{tabular}

${ }^{(1)}$ Médias seguidas de letras iguais, maiúsculas nas linhas e minúsculas nas colunas, dentro de cada fator, não diferem entre si, pelo teste de Tukey, a $5 \%$ probabilidade. ${ }^{(2)}$ Dose de $\mathrm{N}\left(100 \mathrm{~kg} \mathrm{ha}^{-1}\right)$ aplicada a lanço nas épocas: 33 DAS, 33 dias antes da semeadura do feijão (19 dias antes da dessecação das plantas presentes na área); SEM, no mesmo dia da semeadura do feijão; e 23 DAE,-- em cobertura, ao feijoeiro, 23 dias após a emergência. ${ }^{(3)} U$. brizantha 'Marandu'. 
reprodutivas (Crusciol et al., 2007). Soratto et al. (2004) também verificaram aumento do número de vagens do feijoeiro cultivado em SPD, em sucessão ao milho, com a aplicação de N. Segundo Silveira et al., (2005), em sucessão à cultura do milho, o feijoeiro deve receber maior quantidade de $\mathrm{N}$, já que pode haver maior competição dos microrganismos pelo nutriente, durante a decomposição da palhada que, por sua relação $\mathrm{C} / \mathrm{N}$ e tamanho dos resíduos, é mais demorada do que a de outras plantas, principalmente leguminosas.

Nos tratamentos adubados com $\mathrm{N}$, o cultivo anterior da forrageira em consórcio não afetou o número de vagens do feijoeiro (Tabela 5), porque não houve restrição de $\mathrm{N}$ para as plantas (Tabela 3). Porém, quando não foi aplicado $\mathrm{N}$, o feijoeiro cultivado em sucessão ao consórcio produziu mais vagens (Tabela 5). Isso mostra que a presença da forrageira em consórcio com o milho, no cultivo anterior, melhorou a nutrição nitrogenada do feijoeiro em sucessão (Tabela 3 ).

A produtividade de grãos do feijoeiro foi pouco influenciada pela cultura antecessora (Tabela 5). Porém, independentemente da época de aplicação do fertilizante, houve em média $33 \%$ de aumento da produtividade de grãos com a aplicação de $\mathrm{N}$, quando o feijão foi cultivado em sucessão ao milho solteiro. Isto indica que é possível efetuar a antecipação da adubação nitrogenada no feijoeiro cultivado em $\mathrm{SPD}$, já que altas doses de $\mathrm{N}$ no sulco de semeadura podem comprometer a população de plantas (Santos \& Fageria, 2007), e a aplicação em cobertura, além de onerar o custo de produção, pode provocar danos à cultura em consequência do tráfego do maquinário agrícola (Kluthcouski et al., 2006). Em feijoeiro de inverno cultivado em sucessão ao milho, em SPD, também não se observou efeito do parcelamento do $\mathrm{N}$ sobre a produtividade de grãos (Binotti et al., 2007). As adubações nitrogenadas feitas a lanço sobre a palhada de milho, aos 15 dias antes da semeadura ou em cobertura (Barbosa Filho et al., 2009), e sobre a palhada de milho $+U$. brizantha aos 15 ou 30 dias antes da semeadura, no sulco de semeadura ou em cobertura (Binotti, 2009), também não resultaram em diferenças na produtividade de grãos do feijão cultivado em SPD. Nascente et al. (2012) verificaram que, para algumas cultivares de feijão, a aplicação de todo o $\mathrm{N}$ incorporado antes da semeadura resultou em produtividade mais elevada. De acordo com Kluthcouski et al. (2006), elevadas concentrações de nutrientes, nos estádios iniciais de desenvolvimento, podem promover um bom crescimento inicial do feijão em SPD, principalmente pelo fato de que esta cultura absorve mais de $70 \%$ de suas necessidades nutricionais na fase vegetativa, transformando-se em uma planta vigorosa, alta e forte para, futuramente, formar o grão.

No cultivo em sucessão ao milho consorciado, o feijão não respondeu à adubação nitrogenada, e mesmo sem a aplicação de $\mathrm{N}$, a produtividade foi de quase $3.000 \mathrm{~kg} \mathrm{ha}^{-1}$ (Tabela 5). Este resultado mostra que a inclusão da forrageira no cultivo anterior diminui a necessidade de aplicação de $\mathrm{N}$ ao feijoeiro cultivado em sucessão, graças à elevada capacidade de ciclagem de nutrientes da braquiária (Crusciol et al., 2009).

A boa distribuição de chuvas, durante $o$ desenvolvimento da cultura (Figura 1), bem como a ocorrência de precipitações pluviais adequadas, logo após as aplicações de $\mathrm{N}$, provavelmente, favoreceram a disponibilização do $\mathrm{N}$ e o desempenho produtivo do feijoeiro. Além disso, a textura argilosa, o bom teor de matéria orgânica na camada de $0-20 \mathrm{~cm}$ do solo (Tabela 1) e, principalmente, o elevado acúmulo de resíduos em decomposição à superfície do solo podem ter contribuído para reduzir as perdas do $\mathrm{N}$ antecipado (Kluthcouski et al., 2006). Contudo, em solos arenosos, com baixo teor de matéria orgânica, com fertilidade limitada e com reduzida quantidade de resíduos vegetais à superfície, a antecipação do $\mathrm{N}$ pode não ser uma prática eficiente.

\section{Conclusões}

1. O cultivo de Urochloa brizantha 'Marandu' consorciada com milho reduza necessidade de aplicação de $\mathrm{N}$ ao feijoeiro em sucessão, em comparação ao cultivo anterior de milho solteiro.

2. A aplicação antecipada do $\mathrm{N}$ à cobertura vegetal ou no mesmo dia da semeadura da cultura do feijão proporciona produtividade de grãos semelhante à observada com a aplicação em cobertura.

\section{Agradecimentos}

Ao Conselho Nacional de Desenvolvimento Científico e Tecnológico (CNPq), por concessão de bolsa de produtividade em pesquisa; e à Fundação de Amparo à Pesquisa do Estado de São Paulo (Fapesp, processo nº 2007/07536-2), pelo auxílio financeiro.

Pesq. agropec. bras., Brasília, v.48, n.10, p.1351-1359, out. 2013 DOI: $10.1590 / \mathrm{S} 0100-204 X 2013001000006$ 


\section{Referências}

AIDAR, H.; THUNG, M.; OLIVEIRA, I.P. de; KLUTHCOUSKI, J.; CARNEIRO, G.E.S.; SILVA, J.G. da; DEL PELOSO, M.J. Bean production and white mould incidence under no-till system. Annual Report of the Bean Improvement Cooperative, v.43, p.150-151, 2000 .

AMBROSANO, E.J.; TANAKA, R.T.; MASCARENHAS, H.A.A.; RAIJ, B. van; QUAGGIO, J.A.; CANTARELLA, H. Leguminosas e oleaginosas. In: RAIJ, B. van; CANTARELLA, H.; QUAGGIO, J.A.; FURLANI, A.M.C. (Ed.). Recomendações de adubação e calagem para o Estado de São Paulo. 2.ed. Campinas: Instituto Agronômico: Fundação IAC, 1997. p.189-203. (IAC. Boletim técnico, 100).

ARF, M.V.; BUZETTI, S.; ARF, O.; KAPPES, C.; FERREIRA, J.P.; GITTI, D. de C.; YAMAMOTO, C.J.T. Fontes e épocas de aplicação de nitrogênio em feijoeiro de inverno sob sistema plantio direto. Pesquisa Agropecuária Tropical, v.41, p.430-438, 2011. DOI: $10.5216 /$ pat.v41i3.9706.

BARBOSA FILHO, M.P.; COBUCCI, T.; FAGERIA, N.K.; MENDES, P.N. Época de aplicação de nitrogênio no feijoeiro irrigado monitorada com auxílio de sensor portátil. Ciência e Agrotecnologia, v.33, p.425-431, 2009. DOI: 10.1590/ S1413-70542009000200010.

BARBOSA FILHO, M.P.; FAGERIA, N.K.; SILVA, O.F. da. Fontes, doses e parcelamento da adubação nitrogenada em cobertura para feijoeiro comum irrigado. Ciência e Agrotecnologia, v.29, p.69-76, 2005. DOI: 10.1590/S1413-70542005000100008.

BINOTTI, F.F. da S. Manejo do nitrogênio no feijoeiro de inverno em sucessão a milho e Brachiaria em sistema de plantio direto. 2009. 178p. Tese (Doutorado) - Faculdade de Engenharia, Universidade Estadual Paulista, Ilha Solteira.

BINOTTI, F.F. da S.; ARF, O.; ROMANINI JÚNIOR, A.; FERNANDES, F.A.; SÁ, M.E. de; BUZETTI, S. Manejo do solo e da adubação nitrogenada na cultura de feijão de inverno e irrigado. Bragantia, v.66, p.121-129, 2007. DOI: 10.1590/ S0006-87052007000100015.

BORGHI, E.; CRUSCIOL, C.A.C. Produtividade de milho, espaçamento e modalidade de consorciação com Brachiaria brizantha em sistema plantio direto. Pesquisa Agropecuária Brasileira, v.42, p.163-171, 2007. DOI: 10.1590/ S0100-204X2007000200004.

BORGHI, E.; CRUSCIOL, C.A.C.; MATEUS, G.P.; NASCENTE, A.S.; MARTINS, P.O. Intercropping time of corn and palisadegrass or guineagrass affecting grain yield and forage production. Crop Science, v.53, p.629-636, 2013. DOI: 10.2135/ cropsci2012.08.0469.

COSTA, N.R.; ANDREOTTI, M.; GAMEIRO, R. de A.; PARIZ, C.M.; BUZETTI, S.; LOPES, K.S.M. Adubação nitrogenada no consórcio de milho com duas espécies de braquiária em sistema plantio direto. Pesquisa Agropecuária Brasileira, v.47, p.1038-1047, 2012. DOI: 10.1590/ S0100-204X2012000800003.

CRUSCIOL, C.A.C.; NASCENTE, A.S.; MATEUS, G.P.; BORGHI, E.; LELES, E.P.; SANTOS, N.C.B. dos. Effect of intercropping on yields of corn with different relative maturities and palisadegrass. Agronomy Journal, v.105, p.599-606, 2013. DOI: 10.2134/agronj2012.0426.

CRUSCIOL, C.A.C.; SORATTO, R.P.; BORGHI, E.; MATEUS, G.P. Integração lavoura-pecuária: benefícios das gramíneas perenes nos sistemas de produção. Informações Agronômicas, n.125, p.2-15, 2009.

CRUSCIOL, C.A.C.; SORATTO, R.P.; SILVA, L.M. da; LEMOS, L.B. Fontes e doses de nitrogênio para o feijoeiro em sucessão a gramíneas no sistema plantio direto. Revista Brasileira de Ciência do Solo, v.31, p.1545-1552, 2007. DOI: 10.1590/S0100-06832007000600031.

KLUTHCOUSKI, J.; AIDAR, H.; THUNG, M.; OLIVEIRA, F.R. de A. Manejo antecipado do nitrogênio nas principais culturas anuais. Informações Agronômicas, n.113, p.1-24, 2006.

KLUTHCOUSKI, J.; COBUCCI, T.; AIDAR, H.; YOKOYAMA, L.P.; OLIVEIRA, I.P. de; COSTA, J.L. da S.; SILVA, J.G. da; VILELA, L.; BACELlOS, A. de O.; MAgnabosco, C. de U. Sistema Santa Fé - Tecnologia Embrapa: integração lavoura-pecuária pelo consórcio de culturas anuais com forrageiras, em áreas de lavoura, nos sistemas direto e convencional. Santo Antônio de Goiás: Embrapa Arroz e Feijão, 2000. 28p. (Embrapa Arroz e Feijão. Circular técnica, 38).

MALAVOLTA, E.; VITTI, G.C.; OLIVEIRA, S.A. de. Avaliação do estado nutricional das plantas: princípios e aplicações. 2.ed. Piracicaba: Potafós, 1997. 308p.

NASCENTE, A.S.; KLUTHCOUSKI, J.; CRUSCIOL, C.A.C.; COBUCCI, T.; OliVEIRA, P. De. Adubação de cultivares de feijoeiro comum em várzeas tropicais. Pesquisa Agropecuária Tropical, v.42, p.407-415, 2012. DOI: 10.1590/ S1983-40632012000400003.

OLIVEIRA, I.P. de; ARAÚJO, R.S.; DUTRA, L.G. Nutrição mineral e fixação biológica de nitrogênio. In: ARAÚJO, R.S.; RAVA, C.A.; STONE, L.F.; ZIMMERMANN, M.J. de O. (Coord.). Cultura do feijoeiro comum no Brasil. Piracicaba: Potafós, 1996. p.169-221.

SANTOS, A.B. dos; FAGERIA, N.K. Manejo do nitrogênio para eficiência de uso por cultivares de feijoeiro em várzea tropical. Pesquisa Agropecuária Brasileira, v.42, p.1237-1248, 2007. DOI: $10.1590 /$ S0100-204X2007000900004.

SANTOS, H.G. dos; JACOMINE, P.K.T.; ANJOS, L.H.C. dos; OLIVEIRA, V.A. de; OLIVEIRA, J.B. de; COELHO, M.R.; LUMBRERAS, J.F.; CUNHA, T.J.F. (Ed.). Sistema brasileiro de classificação de solos. 2.ed. Rio de Janeiro: Embrapa Solos, 2006. 306p.

SILVEIRA, P.M. da; BRAZ, A.J.B.P.; KLIEMANN, H.J.; ZIMMERMANN, F.J.P. Adubação nitrogenada no feijoeiro cultivado sob plantio direto em sucessão de culturas. Pesquisa Agropecuária Brasileira, v.40, p.377-381, 2005. DOI: 10.1590/ S0100-204X2005000400009.

SORATTO, R.P.; CARVALHO, M.A.C. de; ARF, O. Teor de clorofila e produtividade do feijoeiro em razão da adubação 
nitrogenada. Pesquisa Agropecuária Brasileira, v.39, p.895-901, 2004. DOI: 10.1590/S0100-204X2004000900009.

SORATTO, R.P.; CRUSCIOL, C.A.C.; SILVA, L.M. da; LEMOS, L.B. Aplicação tardia de nitrogênio no feijoeiro em sistema de plantio direto. Bragantia, v.64, p.211-218, 2005. DOI: 10.1590/S0006-87052005000200007.
SOUZA, E. de F.C. de; SORATTO, R.P. Adubação nitrogenada no feijoeiro após milho safrinha consorciado com Urochloa brizantha e Urochloa ruziziensis. Semina: Ciências Agrárias, v.33, p.2669-2680, 2012.

VIEIRA, C. Adubação mineral e calagem. In: VIEIRA, C.; PAULA JÚNIOR, T.J. de; BORÉM, A. (Ed.). Feijão. 2.ed. Viçosa: Ed. da UFV, 2006. p.115-136.

Recebido em 19 de agosto de 2013 e aprovado em 30 de setembro de 2013 